\title{
Virosome, a hybrid vehicle for efficient and safe drug delivery and its emerging application in cancer treatment
}

\author{
HANQING LIU ${ }^{1}$ \\ ZHIGANG TU ${ }^{2 *}$ \\ FAN FENG ${ }^{2}$ \\ HAIFENG $\mathrm{SHI}^{2}$ \\ KEPING CHEN ${ }^{2}$ \\ XIMING $\mathrm{XU}^{1}$ \\ ${ }^{1}$ School of Pharmacy, Jiangsu \\ University, Zhenjiang \\ Jiangsu 212013, China \\ ${ }^{2}$ Institute of Life Sciences \\ Jiangsu University, Zhenjiang \\ Jiangsu 212013, China
}

Accepted February 9, 2015

\begin{abstract}
A virosome is an innovative hybrid drug delivery system with advantages of both viral and non-viral vectors. Studies have shown that a virosome can carry various biologically active molecules, such as nucleic acids, peptides, proteins and small organic molecules. Targeted drug delivery using virosome-based systems can be achieved through surface modifications of virosomes. A number of virosome-based prophylactic and therapeutic products with high safety profiles are currently available in the market. Cancer treatment is a big battlefield for virosome-based drug delivery systems. This review provides an overview of the general concept, preparation procedures, working mechanisms, preclinical studies and clinical applications of virosomes in cancer treatment.
\end{abstract}

Keywords: virosome, drug delivery system, cancer treatment, cancer vaccine

Successful therapies often require delivery systems to transport drugs to their specific targets and promising novel drugs are sometimes discontinued due to the lack of proper delivery methods. Therefore, numerous drug delivery systems have been developed so far; they are usually classified into viral and non-viral vectors (1).

Viral vectors, such as retroviral, adenoviral or lentiviral vectors are generally more efficient in gene delivery than other vectors (2-4), but are not ideal for delivering agents such as synthetic oligonucleotides, proteins or small compounds. In addition, safety issues have greatly limited clinical applications of viral vectors and the concerns include the leaky expression of viral genes, as well as immunogenicity and changes in the host genome structures $(1,5)$. Meanwhile, a variety of non-viral vectors, such as liposomes, polymeric micelles and composite carriers have also been developed for gene and drug delivery (6-8). Non-viral vectors are generally safer but much less efficient in drug delivery compared to viral vectors. Degradation of therapeutic molecules carried by non-viral vectors in endosomes or lysosomes of target cells also limits clinical applications of this kind of vectors $(5,9)$. In order to overcome the limitations of viral and non-viral vectors and

\footnotetext{
*Correspondence; e-mail: zhigangtu@ujs.edu.cn
} 
utilize their advantages, a virosome, a hybrid drug delivery system composed of both viral and non-viral components, was invented.

First prepared by Almeida et al. (10-13), a virosome is composed of a phospholipid bilayer with viral surface glycoproteins protruding from it. Inside a virosome, there is often a cavity that can be utilized to carry organic compounds, nucleic acids or proteins to the target sites (Fig. 1). By mimicking a natural viral infection, virosomes can recognize and bind to specific receptors to enter the target cells; they are therefore very efficient in drug delivery. In addition, since they lack genetic materials of parent viruses, virosomes are generally safe in usage. To date, influenza viruses, hemagglutinating virus of Japan (HVJ or Sendai virus) and several other viruses have been successfully reconstituted to produce virosomes (14-21).

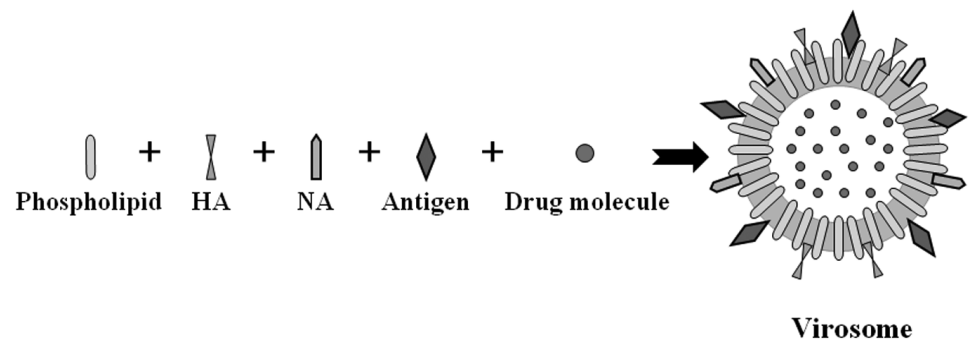

Fig. 1. Composition of a virosome derived from influenza virus. The envelope of influenza virusbased virosome is composed of a phospholipid bilayer which has viral glycoproteins hemagglutinin (HA, cone) and neuraminidase (NA, conical ended cylinder), antigens (diamond) displayed on the surface of the virosomes encapsulated drug molecules (dot).

\section{COMMONLY USED VIROSOMES}

\section{Virosomes reconstituted from influenza viruses}

Virosomes reconstituted from influenza viruses may be the most frequently used ones. The envelope of these virosomes is composed of a phospholipid bilayer; meanwhile, viral glycoproteins, hemagglutinin (HA) and neuraminidase (NA) are frequently displayed on the surface of the virosome. HA is the receptor-binding and membrane fusion protein of influenza; it can form homotrimers and changes its conformations at acidic $\mathrm{pH}$ to become fusion-competent (22-24). The other glycoprotein NA does not only enhance the entry of viruses into cells (25) but also facilitates release of progeny viruses at the budding stage by removing terminal sialic acid from saccharide chains on the host cell surface (26).

\section{Virosomes reconstituted from hemagglutinating virus of Japan}

Due to its highly efficient delivery of nucleic acids, proteins and biologically active macromolecules, the HVJ-derived virosomes are especially promising. These virosomes use hemagglutinating (HN) protein and fusion (F) protein for cell fusion (Fig. 2). HN protein can bind to acetyl-type sialic acid at the host cell surface and the F protein associates with lipids, such as cholesterol, to induce membrane fusion of the virosome and host cells (27). 




Fig. 2. The working mechanism of a HVJ-derived virosome. The envelope of HVJ-based virosome is composed of a phospholipid bilayer which has fusion proteins (F, square) and hemagglutinating protein (HN protein, cylinder) displayed on the surface of the virosomes. Drug molecules (such as organic compounds, proteins, peptides, siRNAs, plasmid DNAs) are first incorporated into these virosomes, then the whole virosome molecules will bind to the receptors and fuse with host membrane through membrane fusion. The incorporated drug molecules are then delivered intracellularly.

\section{PREPARATION OF VIROSOMES}

\section{General methods to prepare virosomes}

In order to prepare virosomes, the virus membrane was first solubilized by using various non-denaturing detergents. Octaethylene glycol mono- $n$-dodecyl ether (C12E8) and Triton X-100 are the most commonly used detergents while other non-ionic detergents can also be used (28). Following solubilization, viral nucleocapsids are removed by ultracentrifugation. The lipid bilayer is then self-assembled to produce virosomes when the detergent is removed. During preparation, other lipids, including cholesterol and phospholipids (for example, phosphatidylcholine, sphingomyelin, phosphatidylethanolamine, and phosphatidylserine), can be added to the membranes. Cationic lipids, including DOTAP (1,2-dioleoyl-3-trimethylammonium-propane), DODAC ( $N, N$-dioleyl- $N, N$-dimethylammonium chloride) and stearylamine, can also be added to the membranes to facilitate the delivery of nucleic acids.

During this process, not only virosomes are formed, but also drugs of both hydrophilic and hydrophobic features can be incorporated into the systems (29-32). Hydrophilic drugs are added into the aqueous systems while hydrophobic drugs are added into the phospholipid mixture to ensure the solubility of the drugs.

Electron microscope-based analysis can be used to determine the size and structure of virosomes. The ultimate sizes of virosomes are usually determined by the nature of the viral protein and the composition of the phospholipid bilayer. HVJ virosomes have a mean diameter of $400-500 \mathrm{~nm}$, while influenza virosomes are generally 150-200 $\mathrm{nm}$ in diameter (33). The size of virosomes is one of the most important factors affecting the interaction between particular virosomes and their target cells (34). 


\section{Administration of virosomes}

Prepared virosomes are often suspended in saline buffers $\left(135-150 \mathrm{mmol} \mathrm{L}^{-1} \mathrm{NaCl}\right)$, which often contain other auxiliary elements (such as calcium chloride, potassium chloride, sodium acetate, sodium lactate) to mimic physiological conditions (35). The concentrations of virosomes are often in the range between 20 and $200 \mathrm{mg} \mathrm{mL}^{-1}$ in their buffers, depending upon the properties of virosome components and particular purposes (29). The formulated virosomes are usually sterilized (for example, through membrane filtration) before they are administrated through parenteral, intravenous, oral, intramuscular, topical or respiratory routes $(36-38)$.

\section{Optimization of virosomes}

Hydrophilic polymers [such as polyethylene glycol, polyacryloylmorpholine, polyvinylpyrrolidone and poly(2-oxazoline)] can be inserted into the envelope of virosomes to elongate their circulation time after systemic delivery (39). More importantly, to achieve a target selecting ability, targeting molecules (such as antibodies) can be conjugated to these hydrophilic polymers and inserted into the membrane of virosomes $(40,41)$.

\section{Application of virosomes as drug delivery systems}

Virosomal systems have been used to deliver almost all forms of drugs, such as organic molecules, proteins, peptides and nucleic acids. The lipid bilayer of virosomes serves to protect these therapeutic materials from degradation by host defense systems (42). De Jonge et al. (43) successfully encapsulated plasmid DNA in reconstituted influenza virosomes, which completely protected the transferring DNA from degradation by nucleases and helped the transfection efficiency to achieve about $90 \%$. Similarly, siRNA can be delivered by virosomes to inhibit the expression of target genes in vitro and in vivo. In order to increase the loading of siRNA into virosomes, cationic lipids such as $\mathrm{N}, \mathrm{N}$-dioleoyl- $\mathrm{N}, \mathrm{N}$ dimethylammonium chloride can be used (44). The delivery efficiency of influenza virosomes is comparable to that when using a commercial liposome such as Lipofectamine ${ }^{\circledR}$ 2000; however, the toxicity of influenza virosomes is much lower than that of Lipofectamine ${ }^{\circledR}$ 2000. In addition, virosomes can also be used to deliver proteins and peptides. For example, the gelonin subunit A of diphtheria toxin has been delivered to target cells by virosomes, as well as ovalbumin (45-47). Strong cytotoxic $\mathrm{T}$ lymphocyte responses can be induced by peptides derived from the influenza nucleoprotein delivered by virosomes. All evidence indicated that the encapsulated peptides and proteins gained access to the cytoplasm $(48,49)$.

\section{Advantages and disadvantages of virosomal drug delivery systems}

The unique characteristics of virosome membranes provide them with features of being biocompatible and biodegradable (35). Once inside the cells, virosomes cannot replicate, ensuring their safety profile. Another merit of virosomes is that they can be broadly applied with almost all forms of drugs, such as small organic molecules, proteins, peptides and nucleic acids. 


\section{Comparison with liposomes}

Liposomes have been considered to be among the most potent vehicles for delivering bioactive molecules both in vitro and in vivo. However, due to the low efficiency of liposomes to fuse with cells, they often do not efficiently deliver encapsulated molecules to the cells. In contrast, virosomes usually guarantee cellular delivery of encapsulated molecules since they contain viral envelope glycoproteins with receptor-binding and membrane-fusion properties (50). Nakamura et al. (51) have shown that oligonucleotides can be intracellularly delivered with up to three times greater efficiency by HVJ-virosomes compared to cationic liposomes.

Another major problem associated with liposomes is their rapid clearance by the body's reticuloendothelial system (52). In contrast, virosomes can deliver bioactive agents to the target cells without being affected by the host defense mechanisms for a period of time. Virosomes often excellently preserve the stability and activity of encapsulated therapeutic agents until the drug molecules are intracellularly delivered $(53,54)$.

\section{Targeted drug delivery by virosomes}

The distribution of drugs in different parts of the body is always an important issue for pharmaceutical scientists. So far, tumor cells, erythrocytes, hepatocytes and cells of the respiratory and gastrointestinal systems have been successfully targeted by virosomes (55, 56). One can tailor virosomes to specific targets by incorporating various ligands such as cytokines, peptides, and monoclonal antibodies on the surface of virosomes (57).

\section{Disadvantages of virosomal drug delivery systems}

Like any other technique, also virosome-based delivery systems have their own disadvantages. One disadvantage is that virosomes might induce immune responses because they often have viral glycoproteins on the surface $(11,58)$. On the other hand, the feature of inducing prophylactic responses can help in establishing virosomes as vaccine and immunological adjuvants. Rapid disintegration in the blood compartment could be another potential issue associated with virosomes. This issue can be overcome by increasing the stability of virosomes or by making virosomes reach targeting sites within a short time after administration.

\section{CLINICAL AND PRECLINICAL APPLICATIONS OF VIROSOMES IN CANCER TREATMENT}

Several virosome-based agents with high safety profiles have been approved by the United States Food and Drug Administration (FDA) for use in humans (59). So far, virosomes have successfully delivered anti-cancer, anti-malarial, anti-bacterial, and anti-fungal agents in vitro and in vivo (60-64). However, because of our research interests, in the current review, we will mostly focus on the application of virosomes in cancer treatment.

\section{Virosomes as an adjuvant delivery system for cancer vaccines}

Cancer immunotherapy represents a new class of cancer treatment which harnesses and enhances the innate activities of the immune system to combat tumors and is increasingly accepted as a treatment option for advanced stages of cancers. This idea is so attrac- 
H. Liu et al:: Virosome, a hybrid vehicle for efficient and safe drug delivery and its emerging application in cancer treatment, Acta Pharm. 65 (2015) 105-116.

tive that Science editors have chosen cancer immunotherapy as one of the Top10 Breakthroughs of 2013. Recent studies have shown that virosomes can be an ideal antigen delivery system for cancer treatment.

Virosomes are ideal vehicles for delivering immunogenic substances in host bodies due to their two reciprocally reinforcing functions when used as vaccines. On one hand, virosomes are good vehicles for transferring the immunogen into the body; on the other hand, they are highly effective as immune adjuvants since their surface viral glycoproteins can stimulate humoral responses in their native conformation $(35,65)$. Once the virosomebased vaccines have been administered, both the cellular and humoral arms of the host immune systems are efficiently activated $(66,67)$. Therefore, virosome-based vaccines are very efficient in arousing immunity responses. It has been reported that two doses of Epaxal, a virosome-based vaccine, administered 12 months apart, offered adults a protection of at least 9 to 11 years (68).

Virosome-formulated vaccines had been used in several preclinical studies and clinical trials for cancer treatment $(48,69-72)$. For example, Schwaninger et al. (73) immunized mice with the truncated protein pNeuECD carried by virosomes. Their results showed that the vaccinated mice generated Neu-specific humoral and cytotoxic immune responses. Furthermore, virosome-carried pNeuECD resulted in significant tumor rejection when compared free pNeuECD in complete Freund's adjuvant.

Cervical cancer is one of the cancers that has been successfully treated by immunotherapy of virosome-formulated vaccines. Virosome-fomulated cervical cancer vaccines have been actively studied recently $(74,75)$. In a murine model system, a vigorous class I MHC-restricted cytotoxic T-lymphocyte (CTL) response against HPV-transformed tumor cells was established by using fusion-active influenza virosomes which contained recombinant human papillomavirus type 16 (HPV16) E7 protein antigen. E7-specific antibody responses were also induced in this study. Conjunction of humoral and cytotoxic immune responses successfully prevented tumor outgrowth in more than $70 \%$ of the animals immunized with E7-containing virosomes. Therefore, this study suggested that the influenza-derived virosomes containing E7 protein represent a promising immunotherapeutic vaccine for the treatment of cervical cancer (74). Walczak et al. (75) also found that virosomes containing the HPV16 E7 protein resulted in high numbers of antigen-specific cytotoxic T lymphocytes (CTL) in mice.

Adamina et al. (76) have already started the tailoring of dedicated advanced liposomal and virosome vectors for the immunotherapy of melanoma due to its recognition as an immunogenic tumor and an unprecedented rise in the incidence of melanoma. Schumacher et al. (77) formulated immunopotentiating reconstituted influenza virosomes (IRIV) to efficiently encapsulate L(27)Melan-A/ Mart-1 (26-35) HLA -A0201 restricted peptide, a melanoma-associated antigen widely used in tumor immunotherapy. They found that this reagent significantly enhanced the generation of L(27)Melan-A/Mart-1(26-35) specific CTL compared to soluble peptides, in particular at low nominal epitope concentrations $\left(<1 \mu \mathrm{g} \mathrm{mL} \mathrm{m}^{-1}\right)$. This highly immunogenic antigenic formulation was suggested for further clinical evaluations of melanoma immunotherapy.

\section{Virosomes as carriers for other bioactive molecules in cancer treatment}

Besides tumor antigens, other bioactive molecules, such as oligonucleotides and small organic compounds that can exert anti-tumor activities may also be delivered by viro- 
somes. Zakaria et al. (78) used Sendai virosomes (which are hepatocytes-specific due to their F protein on the surface) to deliver shRNA against oncogene c-Myc in hepatocarcinoma cells. Their approach induced specific heterochromatization and increased DNA methylation of the $\mathrm{CpG}$ islands around the target loci of shRNA, which ultimately resulted in apoptosis of the targeted hepatocarcinoma cells.

More importantly, virosomes can deliver drugs specifically to the target cancer cells by displaying appropriate molecules (such as antibodies or affibodies) on their surface (65). Recently, cancer cell-specific siRNAs have been delivered using a modified virosome system on which affibody molecules of HER2 (human epidermal growth factor receptor 2, often expressed on breast and ovarian cells) were displayed (79). Magnetic force can also be used to drive virosome-formulated anti-cancer medicines into tumor tissues (80). A novel formulation of Decitabine, based on the use of the erythro-magneto-hemagglutinin virosomes (EMHVs) drug delivery system has been refined by Cinti's team (63). Their EMHV delivery system improved pharmacokinetics/pharmacodynamics of Decitabine, specifically transported the drugs into tumor tissues, and finally induced a significant tumor mass reduction in xenograft models of prostate cancer at a concentration much lower than its therapeutic dose in free form.

\section{Virosomes themselves as anti-cancer reagents}

Surprisingly, recent studies have shown that virosomes may have anti-tumor activities just by themselves. Kurooka et al. (81) have demonstrated that direct injection of the $\mathrm{HVJ}$ envelope into murine colon carcinoma (CT26) tumors growing in syngeneic BALB/C mice can eradicate 60 to $80 \%$ of the tumors by both production of tumor-specific cytotoxic T cells and blocking of regulatory T cell activity. HVJ-E injection has also been shown to inhibit Renca tumor growth by enhancing local CXCL10 expression and systemic NK cell activation (82). In addition, two studies have shown that HVJ-E vector directly killed human prostate cancer cells and glioblastoma cells in vitro and in vivo by inducing apoptosis in tumor cells through activation of interferon-related pathways $(83,84)$. Overall, the anti-tumor benefits of the HVJ envelope may come from induced anti-tumor immune responses and induced apoptosis in tumor cells.

\section{FUTURE PROSPECTS}

As a novel and effective drug-delivery system, virosomes are used for delivering a broad range of biologically active molecules. Many virosome-based, prophylactic and therapeutic products, especially vaccines, have been approved by administration authorities in different countries and are currently available in the market. However, the comprehensive pharmacological profiles and stability of virosomes should be studied thoroughly to verify their long-term reliability as a safe, efficient, and economical way of drug delivery. Moreover, the complicated assay processes for characterizing virosome products hold back the development of virosomes. Efforts, therefore, need to be made in this respect to speed up the development of virosome-based products. In conclusion, virosome-based biopharmaceuticals have a high potential for rapid translation into the clinic with improvements and further tests, especially in the area of cancer treatment. 
Acknowledgments. - This work was supported by the Jiangsu Specially-Appointed Professor Program (H. Liu); Jiangsu Recruitment Program of Leading Creative and Entrepreneurial Talents (H. Liu and Z. Tu); National Natural Science Foundation 81402145 (H. Liu) and 31471294 (Z. Tu); Natural Science Foundation of Jiangsu Province BK20140572 (H. Liu); Start-up Scientific Research Fund for the Returned Oversea Scholars from the Chinese Ministry of Education (Z. Tu); Senior Talent Startup Funds of Jiangsu University 14JDG050 (H. Liu) and 14JDG011 (Z. Tu); the Priority Academic Program Development of Jiangsu Higher Education Institutions (School of Pharmacy and Institute of Life Sciences of Jiangsu University).

Abbreviations, acronyms, symbols. - HVJ - hemagglutinating virus of Japan, HA - hemagglutinin, $\mathrm{NA}$ - neuraminidase, HN - hemagglutinating, F - fusion, DOTAP - 1,2-dioleoyl-3-trimethylammonium-propane, DODAC - N,N-dioleyl- $N, N$-dimethylammonium chloride, FDA - Food and Drug Administration, CTL - cytotoxic T-lymphocyte, MHC - major histocompatibility complex, HPV16 human papillomavirus type 16, IRIV - immunopotentiating reconstituted influenza virosomes, siRNA - small interfering RNA, HER2 - human epidermal growth factor receptor 2, EMHV - erythro-magneto-hemagglutinin virosome, $\mathrm{NK}$ - natural killer.

\section{REFERENCES}

1. I. M. Verma and M. D. Weitzman, Gene therapy: twenty-first century medicine, Annu. Rev. Biochem. 74 (2005) 711-738; DOI: 10.1146/annurev.biochem.74.050304.091637.

2. C. Baum, A. Schambach, J. Bohne and M. Galla, Retrovirus vectors: toward the plentivirus? Mol. Ther. 13 (2006) 1050-1063; DOI: 10.1016/j.ymthe.2006.03.007.

3. C. Li, D. E. Bowles, T. van Dyke and R. J. Samulski, Adeno-associated virus vectors: potential applications for cancer gene therapy, Cancer Gene Ther. 12 (2005) 913-925; DOI: 10.1038/sj.cgt.7700876.

4. L. S. Young, P. F. Searle, D. Onion and V. Mautner, Viral gene therapy strategies: from basic science to clinical application, J. Pathol. 208 (2006) 299-318; DOI: 10.1002/path.1896.

5. R. Wattiaux, N. Laurent, S. Wattiaux-De Coninck and M. Jadot, Endosomes, lysosomes: their implication in gene transfer, Adv. Drug Deliv. Rev. 41 (2000) 201-208.

6. M. S. Al-Dosari and X. Gao, Nonviral gene delivery: principle, limitations, and recent progress, AAPS J. 11 (2009) 671-681; DOI: 10.1208/s12248-009-9143-y.

7. M. Morille, C. Passirani, A. Vonarbourg, A. Clavreul and J. P. Benoit, Progress in developing cationic vectors for non-viral systemic gene therapy against cancer, Biomaterials 29 (2008) 3477-3496; DOI: 10.1016/j.biomaterials.2008.04.036.

8. Y. Kaneda and Y. Tabata, Non-viral vectors for cancer therapy, Cancer Sci. 97 (2006) 348-354; DOI: 10.1111/j.1349-7006.2006.00189.x.

9. J. Zabner, A. J. Fasbender, T. Moninger, K. A. Poellinger and M. J. Welsh, Cellular and molecular barriers to gene transfer by a cationic lipid, J. Biol. Chem. 270 (1995) 18997-9007.

10. I. A. Schaap, F. Eghiaian, A. des Georges and C. Veigel, Effect of envelope proteins on the mechanical properties of influenza virus, J. Biol. Chem. 287 (2012) 41078-41088; DOI: 10.1074/jbc. M112.412726.

11. C. Moser, M. Muller, M. D. Kaeser, U. Weydemann and M. Amacker, Influenza virosomes as vaccine adjuvant and carrier system, Expert Rev. Vaccines 12 (2013) 779-791; DOI: 10.1586/14760584.2013.811195.

12. D. Koppers-Lalic, M. M. Hogenboom, J. M. Middeldorp and D. M. Pegtel, Virus-modified exosomes for targeted RNA delivery; a new approach in nanomedicine, Adv. Drug Deliv. Rev. 65 (2013) 348-356; DOI: 10.1016/j.addr.2012.07.006.

13. J. D. Almeida, D. C. Edwards, C. M. Brand and T. D. Heath, Formation of virosomes from influenza subunits and liposomes, Lancet 2 (1975) 899-901. 
14. R. K. Scheule, Novel preparation of functional Sindbis virosomes, Biochemistry 25 (1986) 42234232.

15. W. A. Petri, Jr. and R. R. Wagner, Reconstitution into liposomes of the glycoprotein of vesicular stomatitis virus by detergent dialysis, J. Biol. Chem. 254 (1979) 4313-4316.

16. K. Metsikko, G. van Meer and K. Simons, Reconstitution of the fusogenic activity of vesicular stomatitis virus, EMBO J. 5 (1986) 3429-3435.

17. A. Helenius, E. Fries and J. Kartenbeck, Reconstitution of Semliki forest virus membrane, J. Cell Biol. 75 (1977) 866-880.

18. A. Helenius, M. Sarvas and K. Simons, Asymmetric and symmetric membrane reconstitution by detergent elimination: Studies with Semliki-Forest-virus spike glycoprotein and penicillinase from the membrane of Bacillus licheniformis, Eur. J. Biochem. 116 (1981) 27-35.

19. T. Uchida, J. Kim, M. Yamaizumi, Y. Miyake and Y. Okada, Reconstitution of lipid vesicles associated with HVJ (Sendai virus) sikes. Purification and some properties of vesicles containing nontoxic fragment A of diphtheria toxin, J. Cell Biol. 80 (1979) 10-20.

20. S. Bagai, A. Puri, R. Blumenthal and D. P. Sarkar, Hemagglutinin-neuraminidase enhances F protein-mediated membrane fusion of reconstituted Sendai virus envelopes with cells, J. Virol. 67 (1993) 3312-3318.

21. A. Vainstein, M. Hershkovitz, S. Israel, S. Rabin and A. Loyter, A new method for reconstitution of highly fusogenic Sendai virus envelopes, Biochim. Biophys. Acta 773 (1984) 181-188.

22. A. Jamali, M. Holtrop, A. de Haan, H. Hashemi, M. Shenagari, A. Memarnejadian, F. Roohvand, F. Sabahi, M. T. Kheiri and A. Huckriede, Cationic influenza virosomes as an adjuvanted delivery system for CTL induction by DNA vaccination, Immunol. Lett. 148 (2012) 77-82; DOI: 10.1016/j.imlet.2012.08.006.

23. S. G. Reed, S. Bertholet, R. N. Coler and M. Friede, New horizons in adjuvants for vaccine development, Trends Immunol. 30 (2009) 23-32; DOI: 10.1016/j.it.2008.09.006.

24. J. J. Skehel and D. C. Wiley, Receptor binding and membrane fusion in virus entry: the influenza hemagglutinin, Annu. Rev. Biochem. 69 (2000) 531-569; DOI: 10.1146/annurev.biochem.69.1.531.

25. M. Ohuchi, N. Asaoka, T. Sakai and R. Ohuchi, Roles of neuraminidase in the initial stage of influenza virus infection, Microbes Infect. 8 (2006) 1287-1293; DOI: 10.1016/j.micinf.2005.12.008.

26. R. Wagner, M. Matrosovich and H. D. Klenk, Functional balance between haemagglutinin and neuraminidase in influenza virus infections, Rev. Med. Virol. 12 (2002) 159-166; DOI: 10.1002/ rmv.352.

27. T. Nakajima, Novel gene transfer systems: intelligent gene transfer vectors for gene medicines, Curr. Top. Med. Chem. 12 (2012) 1594-1602.

28. T. Stegmann, H. W. Morselt, F. P. Booy, J. F. van Breemen, G. Scherphof and J. Wilschut, Functional reconstitution of influenza virus envelopes, EMBO J. 6 (1987) 2651-2659.

29. M. G. Cusi, Applications of influenza virosomes as a delivery system, Hum. Vaccin. 2 (2006) 1-7.

30. E. Soussan, S. Cassel, M. Blanzat and I. Rico-Lattes, Drug delivery by soft matter: matrix and vesicular carriers, Angew. Chem. Int. Ed. Engl. 48 (2009) 274-288; DOI: 10.1002/anie.200802453.

31. G. V. Radha, T. S. Rani and B. Sarvani, A review on proniosomal drug delivery system for targeted drug action, J. Basic Clin. Pharm. 4 (2013) 42-48; DOI: 10.4103/0976-0105.113609.

32. H. I. Chang and M. K. Yeh, Clinical development of liposome-based drugs: formulation, characterization, and therapeutic efficacy, Int. J. Nanomedicine 7 (2012) 49-60; DOI: 10.2147/IJN.S26766.

33. A. K. Dey and I. K. Srivastava, Novel adjuvants and delivery systems for enhancing immune responses induced by immunogens, Expert Rev. Vaccines 10 (2011) 227-251; DOI: 10.1586/erv.10.142.

34. M. L. De Temmerman, J. Rejman, J. Demeester, D. J. Irvine, B. Gander and S. C. De Smedt, Particulate vaccines: on the quest for optimal delivery and immune response, Drug Discov. Today 16 (2011) 569-582; DOI: 10.1016/j.drudis.2011.04.006. 
35. A. Huckriede, L. Bungener, T. Stegmann, T. Daemen, J. Medema, A. M. Palache and J. Wilschut, The virosome concept for influenza vaccines, Vaccine 23 (Suppl. 1) (2005) S26-S38; DOI: 10.1016/j. vaccine.2005.04.026.

36. A. M. Harandi and D. Medaglini, Mucosal adjuvants, Curr. HIV Res. 8 (2010) 330-335.

37. I. Jabbal-Gill, Nasal vaccine innovation, J. Drug Target. 18 (2010) 771-786; DOI: 10.3109/ 1061186X.2010.523790.

38. S. Beg, A. Samad, I. Nazish, R. Sultana, M. Rahman, M. Z. Ahmad and M. Akbar, Colloidal drug delivery systems in vaccine delivery, Curr. Drug Targets 14 (2013) 123-137.

39. S. M. Moghimi and J. Szebeni, Stealth liposomes and long circulating nanoparticles: critical issues in pharmacokinetics, opsonization and protein-binding properties, Prog. Lipid Res. 42 (2003) 463478.

40. E. Waelti, N. Wegmann, R. Schwaninger, A. Wetterwald, C. Wingenfeld, B. Rothen-Rutishauser and C. D. Gimmi, Targeting her-2/neu with antirat Neu virosomes for cancer therapy, Cancer Res. 62 (2002) 437-444.

41. E. Mastrobattista, P. Schoen, J. Wilschut, D. J. Crommelin and G. Storm, Targeting influenza virosomes to ovarian carcinoma cells, FEBS Lett. 509 (2001) 71-76.

42. J. Liu, J. Wu, B. Wang, S. Zeng, F. Qi, C. Lu, Y. Kimura and B. Liu, Oral vaccination with a liposomeencapsulated influenza DNA vaccine protects mice against respiratory challenge infection, J. Med. Virol. 86 (2014) 886-894; DOI: 10.1002/jmv.23768.

43. J. de Jonge, J. M. Leenhouts, M. Holtrop, P. Schoen, P. Scherrer, P. R. Cullis, J. Wilschut and A. Huckriede, Cellular gene transfer mediated by influenza virosomes with encapsulated plasmid DNA, Biochem. J. 405 (2007) 41-49; DOI: 10.1042/BJ20061756.

44. J. de Jonge, M. Holtrop, J. Wilschut and A. Huckriede, Reconstituted influenza virus envelopes as an efficient carrier system for cellular delivery of small-interfering RNAs, Gene Ther. 13 (2006) 400-411; DOI: 10.1038/sj.gt.3302673.

45. L. Bungener, K. Serre, L. Bijl, L. Leserman, J. Wilschut, T. Daemen and P. Machy, Virosome-mediated delivery of protein antigens to dendritic cells, Vaccine 20 (2002) 2287-2295.

46. P. Schoen, A. Chonn, P. R. Cullis, J. Wilschut and P. Scherrer, Gene transfer mediated by fusion protein hemagglutinin reconstituted in cationic lipid vesicles, Gene Ther. 6 (1999) 823-832; DOI: 10.1038/sj.gt.3300919.

47. R. Bron, A. Ortiz and J. Wilschut, Cellular cytoplasmic delivery of a polypeptide toxin by reconstituted influenza virus envelopes (virosomes), Biochemistry 33 (1994) 9110-9117.

48. L. Bungener, A. Huckriede, A. de Mare, J. de Vries-Idema, J. Wilschut and T. Daemen, Virosomemediated delivery of protein antigens in vivo: efficient induction of class I MHC-restricted cytotoxic T lymphocyte activity, Vaccine 23 (2005) 1232-1241; DOI: 10.1016/j.vaccine.2004.09.002.

49. A. Arkema, A. Huckriede, P. Schoen, J. Wilschut and T. Daemen, Induction of cytotoxic T lymphocyte activity by fusion-active peptide-containing virosomes, Vaccine 18 (2000) 1327-1333.

50. Y. Kaneda, Virosomes: evolution of the liposome as a targeted drug delivery system, Adv. Drug Deliv. Rev. 43 (2000) 197-205.

51. N. Nakamura, D. A. Hart, C. B. Frank, L. L. Marchuk, N. G. Shrive, N. Ota, K. Taira, H. Yoshikawa and Y. Kaneda, Efficient transfer of intact oligonucleotides into the nucleus of ligament scar fibroblasts by HVJ-cationic liposomes is correlated with effective antisense gene inhibition, J. Biochem. 129 (2001) 755-759.

52. Y. Krishnamachari, S. M. Geary, C. D. Lemke, and A. K. Salem, Nanoparticle delivery systems in cancer vaccines, Pharm. Res. 28 (2011) 215-236; DOI: 10.1007/s11095-010-0241-4.

53. T. Stegmann, T. Kamphuis, T. Meijerhof, E. Goud, A. de Haan and J. Wilschut, Lipopeptide-adjuvanted respiratory syncytial virus virosomes: A safe and immunogenic non-replicating vaccine formulation, Vaccine 28 (2010) 5543-5550; DOI: 10.1016/j.vaccine.2010.06.041. 
54. M. Shafique, J. Wilschut and A. de Haan, Induction of mucosal and systemic immunity against respiratory syncytial virus by inactivated virus supplemented with TLR9 and NOD2 ligands, Vaccine 30 (2012) 597-606; DOI: 10.1016/j.vaccine.2011.11.054.

55. R. J. Cox, G. Pedersen, A. S. Madhun, S. Svindland, M. Saevik, L. Breakwell, K. Hoschler, M. Willemsen, L. Campitelli, J. K. Nostbakken, G. J. Weverling, J. Klap, K. C. McCullough, M. Zambon, R. Kompier and H. Sjursen, Evaluation of a virosomal H5N1 vaccine formulated with Matrix M adjuvant in a phase I clinical trial, Vaccine 29 (2011) 8049-8059; DOI: 10.1016/j.vaccine.2011.08.042.

56. M. D. Joshi, W. J. Unger, G. Storm, Y. van Kooyk and E. Mastrobattista, Targeting tumor antigens to dendritic cells using particulate carriers, J. Control. Release 161 (2012) 25-37; DOI: 10.1016/j.jconrel.2012.05.010.

57. D. Felnerova, J. F. Viret, R. Gluck and C. Moser, Liposomes and virosomes as delivery systems for antigens, nucleic acids and drugs, Curr. Opin. Biotech. 15 (2004) 518-529; DOI: 10.1016/j.copbio.2004.10.005.

58. G. Leroux-Roels, Unmet needs in modern vaccinology: adjuvants to improve the immune response, Vaccine 28 (Suppl. 3) (2010) C25-C36; DOI: 10.1016/j.vaccine.2010.07.021.

59. P. Nordly, H. B. Madsen, H. M. Nielsen and C. Foged, Status and future prospects of lipid-based particulate delivery systems as vaccine adjuvants and their combination with immunostimulators, Expert Opin. Drug Deliv. 6 (2009) 657-672; DOI: 10.1517/17425240903018863.

60. P. G. Cech, T. Aebi, M. S. Abdallah, M. Mpina, E. B. Machunda, N. Westerfeld, S. A. Stoffel, R. Zurbriggen, G. Pluschke, M. Tanner, C. Daubenberger, B. Genton and S. Abdulla, Virosome-formulated Plasmodium falciparum AMA-1 \& CSP derived peptides as malaria vaccine: Randomized phase $1 \mathrm{~b}$ trial in semi-immune adults \& children, PLoS One 6 (2011) e22273; DOI: 10.1371/journal. pone.0022273.

61. A. Cassone and A. Casadevall, Recent progress in vaccines against fungal diseases, Curr. Opin. Microbiol. 15 (2012) 427-433; DOI: 10.1016/j.mib.2012.04.004.

62. J. Torresi, D. Johnson and H. Wedemeyer, Progress in the development of preventive and therapeutic vaccines for hepatitis C virus, J. Hepatol. 54 (2011) 1273-1285; DOI: 10.1016/j.jhep.2010.09.040.

63. I. Naldi, M. Taranta, L. Gherardini, G. Pelosi, F. Viglione, S. Grimaldi, L. Pani and C. Cinti, Novel epigenetic target therapy for prostate cancer: a preclinical study, PLoS One 9 (2014) e98101; DOI: 10.1371/journal.pone.0098101.

64. R. M. Roy and B. S. Klein, Dendritic cells in antifungal immunity and vaccine design, Cell Host Microbe 11 (2012) 436-446; DOI: 10.1016/j.chom.2012.04.005.

65. A. Huckriede, L. Bungener, W. ter Veer, M. Holtrop, T. Daemen, A. M. Palache and J. Wilschut, Influenza virosomes: combining optimal presentation of hemagglutinin with immunopotentiating activity, Vaccine 21 (2003) 925-931.

66. E. Nardin, The past decade in malaria synthetic peptide vaccine clinical trials, Hum. Vaccin. 6 (2010) 27-38.

67. J. Wilschut, Influenza vaccines: the virosome concept, Immunol. Lett. 122 (2009) 118-121; DOI: 10.1016/j.imlet.2008.11.006.

68. C. Hatz, R. van der Ploeg, B. R. Beck, G. Frosner, M. Hunt and C. Herzog, Successful memory response following a booster dose with a virosome-formulated hepatitis a vaccine delayed up to 11 years, Clin. Vaccine Immunol. 18 (2011) 885-887; DOI: 10.1128/CVI.00358-10.

69. W. Z. Zhou, D. S. Hoon, S. K. Huang, S. Fujii, K. Hashimoto, R. Morishita, and Y. Kaneda, RNA melanoma vaccine: induction of antitumor immunity by human glycoprotein 100 mRNA immunization, Hum. Gene Ther. 10 (1999) 2719-2724; DOI: 10.1089/10430349950016762.

70. M. G. Cusi, M. T. Del Vecchio, C. Terrosi, G. G. Savellini, G. Di Genova, M. La Placa, F. Fallarino, C. Moser, C. Cardone, G. Giorgi, G. Francini and P. Correale, Immune-reconstituted influenza virosome containing CD40L gene enhances the immunological and protective activity of a carcinoembryonic antigen anticancer vaccine, J. Immunol. 174 (2005) 7210-7216. 
71. P. Correale, M. T. Del Vecchio, T. Renieri, G. Di Genova, M. La Placa, C. Remondo, G. G. Savellini, C. Terrosi, R. Zurbriggen, M. Amacker, G. Francini and M. G. Cusi, Anti-angiogenetic effects of immune-reconstituted influenza virosomes assembled with parathyroid hormone-related protein derived peptide vaccine, Cancer Lett. 263 (2008) 291-301; DOI: 10.1016/j.canlet.2008.01.018.

72. U. Wiedermann, C. Wiltschke, J. Jasinska, M. Kundi, R. Zurbriggen, E. Garner-Spitzer, R. Bartsch, G. Steger, H. Pehamberger, O. Scheiner and C. C. Zielinski, A virosomal formulated Her-2/neu multi-peptide vaccine induces Her-2/neu-specific immune responses in patients with metastatic breast cancer: a phase I study, Breast Cancer Res. Treat. 119 (2010) 673-683.

73. R. Schwaninger, E. Waelti, P. Zajac, A. Wetterwald, D. Mueller and C. D. Gimmi, Virosomes as new carrier system for cancer vaccines, Cancer Immunol. Immunother. 53 (2004) 1005-17; DOI: 10.1007/ s00262-004-0545-5.

74. L. Bungener, A. de Mare, J. de Vries-Idema, P. Sehr, A. van der Zee, J. Wilschut and T. Daemen, A virosomal immunization strategy against cervical cancer and pre-malignant cervical disease, $A n$ tivir. Ther. 11 (2006) 717-727.

75. M. Walczak, A. de Mare, A. Riezebos-Brilman, J. Regts, B. N. Hoogeboom, J. T. Visser, M. Fiedler, P. Jansen-Durr, A. G. van der Zee, H. W. Nijman, J. Wilschut and T. Daemen, Heterologous primeboost immunizations with a virosomal and an alphavirus replicon vaccine, Mol. Pharm. 8 (2011) 65-77; DOI: 10.1021/mp1002043.

76. M. Adamina, R. Schumacher, P. Zajac, W. P. Weber, R. Rosenthal, C. Groeper, C. Feder, R. Zurbriggen, M. Amacker, G. C. Spagnoli, D. Oertli and M. Heberer, Advanced liposomal vectors as cancer vaccines in melanoma immunotherapy, J. Liposome Res. 16 (2006) 195-204; DOI: 10.1080/ 08982100600848546.

77. R. Schumacher, M. Amacker, D. Neuhaus, R. Rosenthal, C. Groeper, M. Heberer, G. C. Spagnoli, R. Zurbriggen and M. Adamina, Efficient induction of tumoricidal cytotoxic T lymphocytes by HLA-A0201 restricted, melanoma associated, L(27)Melan-A/MART-1(26-35) peptide encapsulated into virosomes in vitro, Vaccine 23 (2005) 5572-5582; DOI: 10.1016/j.vaccine.2005.07.099.

78. M. K. Zakaria, I. Khan, P. Mani, P. Chattopadhyay, D. P. Sarkar and S. Sinha, Combination of hepatocyte specific delivery and transformation dependent expression of shRNA inducing transcriptional gene silencing of c-Myc promoter in hepatocellular carcinoma cells, BMC Cancer 14 (2014) 582; DOI: 10.1186/1471-2407-14-582.

79. Y. Nishimura, H. Mieda, J. Ishii, C. Ogino, T. Fujiwara and A. Kondo, Targeting cancer cell-specific RNA interference by siRNA delivery using a complex carrier of affibody-displaying bio-nanocapsules and liposomes, J. Nanobiotechnol. 11 (2013) 19; DOI: 10.1186/1477-3155-11-19.

80. C. Cinti, M. Taranta, I. Naldi and S. Grimaldi, Newly engineered magnetic erythrocytes for sustained and targeted delivery of anti-cancer therapeutic compounds, PLoS One 6 (2011) e17132; DOI: 10.1371/journal.pone.0017132.

81. M. Kurooka and Y. Kaneda, Inactivated Sendai virus particles eradicate tumors by inducing immune responses through blocking regulatory T cells, Cancer Res. 67 (2007) 227-236; DOI: 10.1158/ 0008-5472.CAN-06-1615.

82. A. Fujihara, M. Kurooka, T. Miki and Y. Kaneda, Intratumoral injection of inactivated Sendai virus particles elicits strong antitumor activity by enhancing local CXCL10 expression and systemic NK cell activation, Cancer Immunol. Immunother. 57 (2008) 73-84; DOI: 10.1007/s00262-007-0351-y.

83. M. Tanaka, T. Shimbo, Y. Kikuchi, M. Matsuda and Y. Kaneda, Sterile alpha motif containing domain 9 is involved in death signaling of malignant glioma treated with inactivated Sendai virus particle (HVJ-E) or type I interferon, Int. J. Cancer. 126 (2010) 1982-1991; DOI: 10.1002/ijc.24965.

84. Y. Kawaguchi, Y. Miyamoto, T. Inoue and Y. Kaneda, Efficient eradication of hormone-resistant human prostate cancers by inactivated Sendai virus particle, Int. J. Cancer 124 (2009) 2478-2487; DOI: 10.1002/ijc.24234. 